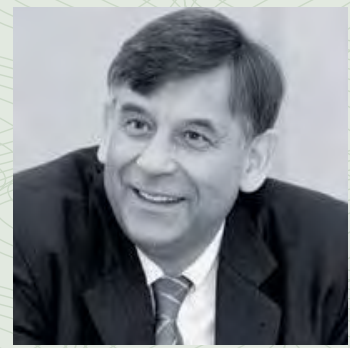

Hermann Simon is the chairman of the strategy and marketing consultancy Simon-Kucher \& Partners, which has offices in eighteen cities around the world. He is an expert in strategy, marketing and pricing, and was recently voted the most influential management thinker since Peter Drucker.

Professor Simon has published over thirty books in sixteen languages, including the definitive Preismanagement (1992), the worldwide bestseller Hidden Champions (1996), Power Pricing (1997), Das große Handbuch der Strategiekonzepte (2000), Simon for Managers (2001), Strategy in Competition (2003), and Think (2004). Manage for Profit, Not for Market Share was published in 2006. This provocative book takes a critical look at the widespread focus on volume and market share and calls for a conscious shift of focus towards profit. His most recent book, Hidden Champions of the 21st Century (New York 2009) investigates the strategies of little-known world market leaders.

Before committing himself fulltime to the management consulting business, simon was professor of business administration and marketing at the universities of Mainz (1989-1995) and Bielefeld (1979-1989). He was also a visiting professor at various international universities: Harvard Business School, Stanford, London Business School, INSEAD, Keio University in Tokyo, and the Massachusetts Institute of Technology. Between 1985 and 1988 he was the director of the Universitätsseminar der Wirtschaft (now the European School of Management and Technology) at Schloss Gracht in Cologne. •

\section{THE INTERVIEWER}

This interview was conducted in Bonn on November 25, 2008 by the editor-in-chief, Professor Hermann Diller

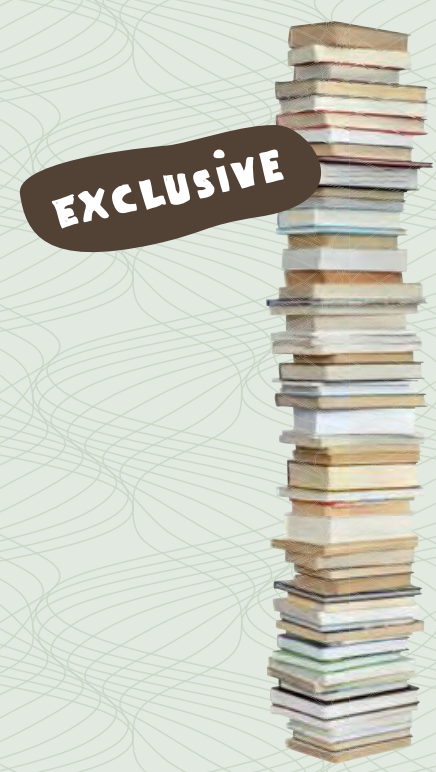




\title{
MIR TALKS TO PROFESSOR HERMANN SIMON
}

\author{
Conducted by Hermann Diller
}

MIR: Hermann Simon, you're in virtually daily contact with highranking decision makers in marketing. Do you think they've become more professional in recent years?

SIMON: Professionalism in marketing is definitely increasing, especially from a long-term perspective. However, it also varies a great deal between sectors and companies. It starts high up. If senior managers require decision-making support that's underpinned by data, they'll get it, and this creates a fact-based culture. But if leadership is based more on gut feeling, which may include arbitrary decisions at times, then marketing does not become more professional.

MIR: Does market research play a key role in this positive trend? In other words, is professionalism linked to market research, or are we talking about a different type of professionalism?

SIMON: Market research plays an important role, but the correlation between market research and decision-making is even more important. I'd describe it as a debate. Companies with a high level of professionalism spend a lot of time and energy on this debate, continuously questioning what works, modeling different scenarios, and talking to other people.

Premium car manufacturers will normally commission not one but two market research studies when making important decisions, so they can examine the issue in depth and obtain a second opinion, just as you would in medicine. If the two opinions agree, you can be reasonably sure you're doing the right thing. If they're contradictory, you might even have to get a third opinion. This debate is extremely important, right through from collecting the raw data to implementing the decision and ensuring that it's accepted, for example by your sales department.
MIR: How important is professionalism compared to all the other skills you'd expect of a good manager, such as a willingness to take risks, entrepreneurship, and strength of leadership?

SIMON: Well, expressing it in figures, I'd say it counts for 50 percent of the total skills you need.

MIR: That much?

SIMON: Yes. Let me give you an example. It takes a lot of entrepreneurial courage to deviate from previous practice because the facts tell you that you should. Porsche's Cayman model - which was derived from the Boxster - was launched three years ago. The Boxster was a convertible, but the Cayman is a hardtop. The sector practice is that convertibles consistently cost about 10 percent more than hardtops, and hardtops 10 percent less than convertibles.

In the case of Porsche, exactly the opposite was implemented, with the basic Boxster model costing $€ 52,000$ and the Cayman being launched with a price of $€ 58,000$. Such an approach requires very determined entrepreneurship, the kind that only a strong manager like Porsche's CEO, Wendelin Wiedeking, can muster.

MIR: Was this decision based on analysis?

SIMON: It was based on very careful analysis, using a variety of methods, in Europe and worldwide. We also know of cases where the very opposite happens. For example, we were recently working with a manager who said: "Yes, we'll do a pricing project now, but on one condition: we mustn't lose a single customer as a result. If the newspapers say that we've lost a customer or our market share has decreased, I'm in the firing line." 
MIR: You recently said in a paper on the practical role of marketing science that decision support systems are one of the big success stories of marketing. To be honest, that surprised me, because we saw a similar optimism about management information systems in the 1970s, but it soon gave way to disillusionment. It's surprising that these systems, which are basically about automated decision-making, are experiencing something of a renaissance. Are we handing over our professionalism to computers?

SIMON: No. Here again, interpreting data, using it to make decisions and then getting these decisions accepted is still hugely important. I would strongly reject the notion of automation in this context. The decision-making models are not automated models that managers use in day-to-day business, looking at them once a week or once a month and saying, "Okay, let's enter some new data and use it to generate a new decision." They're decision support models that are used to make important decisions like new product launches, repositioning, and responding to things your competitors do, but they're always carefully re-examined.

This is not compatible with what John Little said in 1971, which was that computers would one day provide ready-made decisions for managers. Today's models are a mix of quantitative analysis and the very important input from people with an in-depth understanding of the model and the market.

MIR: Apart from conjoint analysis, what other models do you use?

SIMON: One method that's very important to us is expert judgment. This means that the experts, usually the company's own sales and marketing people, retailers and others, give their assessments of the effects of certain actions. For example, when you've got a completely new product such as a drug with new therapeutic indications, the doctors who prescribe it are not generally in a position to make a judgment about it. In these cases, we also survey the medical

\section{») Creativity and marketing intelligence are} completely intertwined, because the basis of everything is the value that you deliver to customers, and it takes creativity to create value. « researchers who've tested the product. Focus groups are also important. The findings are obviously not just entered quantitatively in the models, but they supplement the information and help to produce a sound overall assessment.

MIR: Do you include them in something like a market success simulation model?

SIMON: Yes. Simulation models are a big step forward, and perhaps we should be talking more about simulation models than decision support models.

MIR: You've mentioned pricing and new product decisions, but are there any other areas where these models can be used?

SIMON: Sales is one big area, of course.

MIR: And which particular issues?

SIMON: How should you use your sales team, do you have too few or too many salespeople, how do you manage sales? Incentives are also an important issue, and here we use simulation models as well as conjoint analysis in some cases. For example, you might carry out a conjoint analysis of the sales staff, presenting them with alternative incentive systems and asking which they prefer. Expert opinions are also very important.

We don't use these quantitative models to measure advertising efficiency very often, but that may be partly because we specialize more in products, prices and sales.

MIR: Why does distribution rarely feature in decision support models or the brief for consultants?

SIMON: Because distribution - for example, of cars or pharmaceuticals - is more fixed and provides less leeway for optimization. It's a different matter for the direct sales companies we work with, where distribution itself is a central element, perhaps the most important, and selecting and assessing potential customers and managing sales staff and distributors are all crucial.

MIR: What's the role of creativity in this context? Is there are any scope for it in marketing intelligence?

SIMON: Creativity and marketing intelligence are completely intertwined, because the basis of everything is the value that you deliver to customers, and it takes creativity to create value. There are two facets to this. One is what you're objectively offering with your product or service, and the other is how you communicate and position it.

New pharmaceuticals are a very important area for us - I mean genuine, major innovations. It's always a big decision whether to focus more on the drug's primary effect, or on its safety and absence of side effects, and you have to talk about how you take it, and the dosage. We check these value-to-customer aspects extremely carefully, because the price must always reflect the value to the customer. Value is the key aspect of pricing. 
MIR: But isn't this more in qualitative terms?

SIMON: No, it also applies quantitatively. If you use conjoint analysis, all of this is quantified.

MIR: But if you're going to define specific features, you need to know which are relevant.

SIMON: Of course you need a creative approach when you're communicating the benefits of the product and deciding which to focus on. There's a lot of need for dual creativity in high-tech sectors such as software, hardware and telecoms - by dual creativity I mean producing innovations and then communicating them cleverly.

MIR: People in marketing are increasingly using the term 'marketing intelligence' rather than 'market research'. In your opinion, what does marketing intelligence mean in practice?

SIMON: Compared with intelligence in terms of obtaining information and interpreting data, in other words traditional market research, I'd interpret this term more widely and say that marketing intelligence means having the broadest and deepest possible understanding of consumers, the benefits you can give them as a company, and what they think of this. In my experience, we have a huge amount of catching up to do in terms of marketing intelligence.

MIR: So it's not just a coincidence that businesses now want to know so much more about their customers?

SIMON: No, it most certainly isn't a coincidence. On the contrary, it's the central issue.

MIR: We're inundated with knowledge, but we don't know what it all means.

SIMON: Yes. And the problem is much more serious for large companies than for SMEs. Why? Because large companies are much more distanced from their customers. I've found that with the little-known but highly successful businesses I call hidden champions, 25 to 50 percent of staff have regular customer contact, compared to between 5 and 10 percent for large companies. This means that 90 to 95 percent don't talk to their customers on a frequent basis, and it's especially true of staff in R\&D and along the supply chain. So lack of customer insight is a major issue for big companies.

MIR: They don't know enough about what their customers are like and how they think?

SIMON: No. We worked with a major tire manufacturer once, and talking of creativity - we decided to launch a range of tires which were differentiated on the basis of the time it took to deliver them. The ability to deliver is a key issue in selling tires, especially during the periods when drivers switch from summer to winter tires and vice versa. Dealerships don't want to stockpile; they want to obtain the goods instantly when they need them.

So we turned one product into three different products. Type $X 53$ is now available as X533, X537 and X5314. "3" indicates three days'

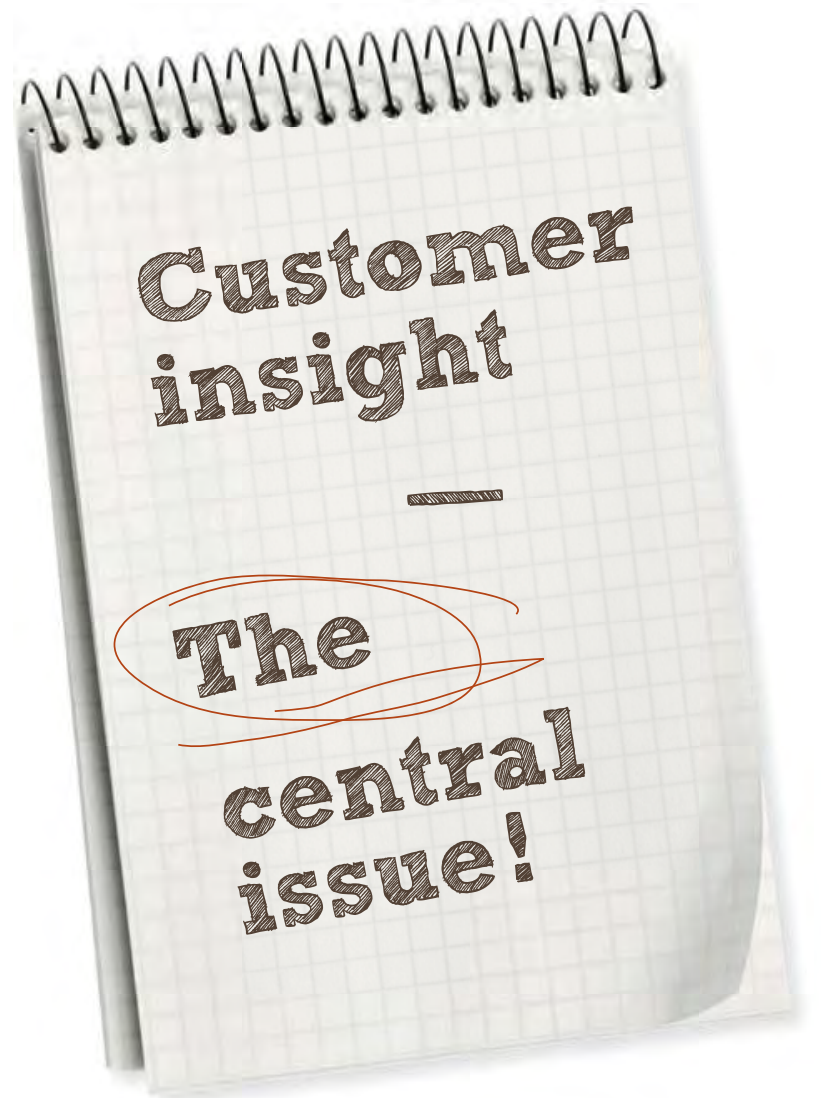

delivery time and the price of this tire is higher than that of the X537, which has a delivery time of seven days. This in turn is more expensive than the X5314, which is supplied within fourteen days. The difference in prices reflects customer preferences in terms of delivery times. From the point of view of the company's logistics and supply chain management, this was a completely new approach. For the first time, these departments were not just processing units, but became decisive in generating value. And this value has now been quantified for the first time. Of course, dealerships still negotiate discounts, but they do it based on the list prices of type 3, type 7 and type 14 .

MIR: Generally speaking, insight is associated more with qualitative market research - studio and group discussions and depth interviews. Is this how it should be? Or can insight also be obtained from traditional cross-sectional business management analysis and standardized surveys?

SIMON: Both are relevant. Purely qualitative information is not helpful, because decisions always need to be quantitative. You have to decide how much to spend, how much of the sales force budget to add and how many campaigns to implement, and then determine the price on this basis. This means that, ultimately, your decisions always need to have a quantitative dimension. Of course, you might have to choose between visual A and visual B in your advertising, which is obviously not quantitative, but even here you need a quantitative assessment of the effect. 


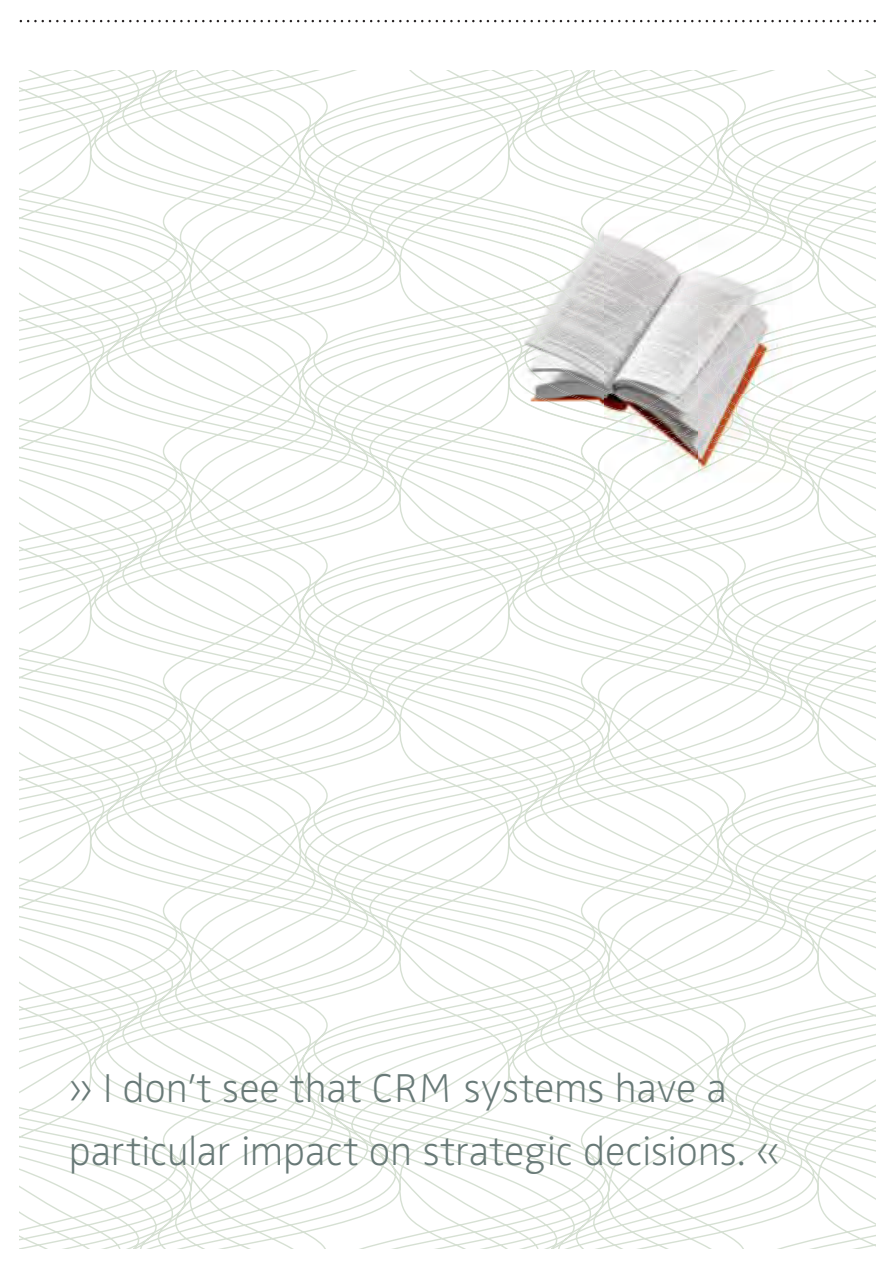

I was talking to a car manufacturer yesterday, and he told me that what he was ultimately interested in was the end result, so he could plan his production capacity and other things accordingly. The methods used along the way, both qualitative and quantitative, were of secondary importance to him, and he said that in that respect, he had to rely on us getting it right.

However, at the same time he did expect us to use all the tools we had access to. In his particular case, we implemented focus groups as well as analyzing the actual market in terms of its response to certain situations. We didn't use an econometric approach; we simply used the tools of the trade, like conjoint-style surveys and car clinics. He expected us to include all these methods. This is customer insight assessing the situation, using different methods and approaches to establish what customers think, how they respond and how they view product benefits.

MIR: Why are so many companies using consultants rather than their own market researchers, assuming they still have any? How did this decline in in-house market research come about?
SIMon: Well, even major companies no longer have staff with this specialist expertise, and there are several reasons for this. Firstly, good people can develop their careers in big companies. I'll give you an example. Twelve years ago, we did a large-scale project for Daimler and had a team of their top people on board, outstanding people. When we worked with them two years later, they'd moved on. One had gone to the US, another had become a line manager, and so on. Of course, they were all keen to move on rather than staying in the same department. In a consultancy firm, people are more likely to stay in specific jobs, because they represent the firm's core competence.

Another reason is that even large companies that still maintain big market research departments still want to know what's happening in other companies. They want to learn from our experience in other sectors and companies and see the benchmarks. Obviously, an in-house department can't provide this information.

MIR: Could we go even further and say that marketing intelligence has to rely on external professionals and input, if nothing else because it offers economies of scale and wide-ranging experience?

SIMon: Probably also because external companies have greater staff mobility. We've hired around 100 people each year for several years, and this brings new knowledge from universities, research and doctoral theses into our company. A manufacturer can't generate such a big influx of new and specialist expertise.

MIR: Marketing decision makers take pride in the concepts of customer and brand value, because they're ways of proving that marketing impacts shareholder value. Is this pure fantasy, or is it true?

SIMON: Well, if you look at the situation today, it's wishful thinking rather than reality. It's not too common to see customer and brand value quantified and translated into shareholder value, and in practice, this kind of thinking is not really quantitative. This is partly due to the availability of data, and also to the extent to which pressure can be put on things like loyalty ratios. I would say it's reflected most clearly when estimating customer acquisition costs and budgets, where you can determine the value of your customers and thus how much you can spend on each one.

This in turn is most pronounced in sectors where individual customer data is available and the customer's history can be traced, such as telecommunications, airlines, insurance companies, banks and other service providers - in other words, companies that know the value of their customers. Interestingly enough, B-to-B marketing has essentially always had this. However, it's rarely had the analytical capabilities required to fully exploit this data.

MIR: This leads us neatly on to CRM systems, which generate customer value data and are designed to provide information about the relevant driving forces. What's your opinion of these systems?

SIMON: In practice, except for the cases I mentioned, I don't see that CRM systems have a particular impact on strategic decisions. From my 
point of view, they continue to be geared more toward operational sales management and direct mailing campaigns. In terms of how to build a customer base and whether you should dump certain customers because they're not profitable, I believe CRM systems have little influence at the strategic level.

MIR: Some tools don't necessarily have to be used for strategic purposes. There are plenty of operational decisions where they can achieve significant cost savings.

SIMON: Of course, nobody should belittle the achievements of operational management. But there's one more thing which I believe is important in connection with CRM systems, and which comes up frequently in our discussions with clients, especially in the car industry. It's the need to set appropriate limits for your analysis, and to focus on the relevant target group, which is something that's often completely neglected in market research.

Market researchers tend to home in on representiveness. For example, they'll try to map out the market representatively, whereas we'll often start with a simpler question, such as "Would you, as a customer, consider buying an Opel?" Some people will say no, although in terms of representative aspects such as purchasing power, they'd be in the target group. There's often a dispute as to whether such customers who express specific preferences and dislikes should be included in the analysis at all. We say no. You can't overcome such preferences by modifying a product or a price, nor through a mailshot.

Take this example: when Mercedes launched the A series in 1998, it had a polarizing effect. Twenty-five percent of the people interviewed said they liked it, and 75 percent didn't. First, we conducted an extensive telephone survey, simply asking respondents whether they'd heard of the A series and whether they'd buy it. The 75 percent who said that they wouldn't were excluded from the in-depth survey on the basis of follow-on considerations. Although our sample was no longer representative, it hit the mark because we focused on people who did like the model. The others were of no strategic interest.

MIR: This is also reflected in the development of conjoint measurement, where choice-based conjoint options are increasingly used as well as the limit-card method. This raises the methodological question of whether conjoint analysis, which your company uses extensively, really is reliable enough. As you're no doubt aware, scientific validity studies have shown that the forecasting accuracy of conjoint analysis is not that great. So why is it used so frequently?

SIMON: Well, in my opinion, selecting respondents is just as important as the actual intrinsic methodology you use, be it conjoint analysis or another method. For example, if you'd said of the Mercedes A series: "Yes, this is a mass-market car that will compete with the VW Golf and all sorts of mass production models, so let's conduct a representative survey in this segment," you'd have been way off the mark.

MIR: But the sales forecast did assume that it related only to a section of the market. So it wasn't applied blindly, but...
SIMON: No, there was no blind application of a standard model. Corrective adjustments were made in line with the actual market, and these were then included in the simulation.

MIR: Are there any other new methodologies in market research which are of particular interest to marketing consultancy, and which are accepted in practice? For example, Bayes models with hierarchical dependency analysis, diffusion models and logit models, in which qualitative variables are also modeled in some dependencies?

SIMON: Well, things like logit models and Bayes are likely to be more widely used. We use them ourselves occasionally, but alongside others. And as far as diffusion models are concerned, I'll stick to my opinion. The problem is that you don't really have a database at the outset, so if you calibrate the model on the basis of a test market or the first few months, the uncertainty is simply too great. I prefer to make subjective projections based on expert opinions and direct surveys.

Another method which is very important is Van Westendorp's price sensitivity meter. This is one we use a lot, always to supplement other systems, because it doesn't provide quantitative data on the pricedemand function, but it does help when you're evaluating results.

MIR: What about the future of cluster analysis? Do you use latent class analysis with probabilistic clusters, for example?

SIMON: Not as far as I'm aware. However, segmentation is very important, although the key issue is not whether you could apply an even more sophisticated segmentation method. The approach is rather more pragmatic, and involves simulating the various multivariate building blocks using cluster or discriminant analysis and similar methods. And there's probably a certain amount of time lag between new methods being developed at universities and actually being applied

\section{» Selecting respondents is just as important as the actual intrinsic methodology you use, be it conjoint analysis or another method. «}




\section{») Price cuts, hoping this will help to maintain volume, is a complete illusion because all competitors follow suit, so both prices and volumes are low - the worst of both worlds. «}

MIR: Let's talk just a little more about market segmentation. Isn't this becoming more and more complex in markets where any description of consumer behavior has to be truly multidimensional if it's to be accurate?

SIMON: The market has certainly become more differentiated, but this is partly because it's grown so much. Take the global automotive industry, which is making almost 80 million cars a year. Ten years ago the figure was only 40 million, so even if you address a very small segment of this market, in absolute terms it's much larger than before, so it's worth carrying out this analysis. It's precisely the fact that markets have become more fragmented and differentiated that makes this analysis all the more important.

For example, 10 million SUVs are made each year; twenty years ago, this segment hardly even existed, and only park rangers used them. Another 10 million are economy cars like the Tata Nano and the Renault Dacia, and this number is forecast to rise to 27 million by 2015. We need to understand these segments in detail: for example, why is the ultra-low price segment growing twice as fast as the automotive market overall?

MIR: Let's end by talking about the coming months and years. How can marketing intelligence help to deal with the current state of the economy, and what demands will be made of it? Will this also be a problem for market research?

SIMON: In a recession, companies often respond by cutting all their costs. I think that's a serious mistake, because this recession is so extreme that cost savings alone will not save them. This is a revenue crisis, not a cost crisis. If sales are down by 30 percent and you achieve cost savings of 15 percent, this is still not good enough. This is where marketing expertise should be used. Reducing the supply of products is a big issue, for example, both for individual companies and sectors as a whole; the demand curve is what counts, and if you want to maintain reasonably stable prices, you need to reduce supply. As a rule, this is much better than accepting a decline in prices.

Companies tend to do the exact opposite. They cut prices, hoping this will help them maintain volume, which is a complete illusion because all their competitors follow suit, so both prices and volumes are low - the worst of both worlds. They need to exploit every opportunity to realize additional sales, for example by raising price parameters, to which hardly any attention is paid, and promoting service.

Service has been neglected in recent years because everyone has had production bottlenecks. If a sales organization is working below capacity, it should try to include third-party products. We've just implemented this approach with two well-known confectionery manufacturers, who began selling each other's products. As you can see, there are plenty of opportunities on the marketing and sales front that companies can use to prevent a further decline in sales volume. This is a key issue in the current crisis.

MIR: Are there any other factors which we haven't mentioned but you think marketing intelligence experts should be taking notice of?

SIMON: Yes, globalization. Globalization is very important to the German economy, perhaps even the most important issue. So far, we've been very successful. Our exports - I was in Russia and China recently - exceed the gross national product of Russia. Keeping track of numerous and increasingly complex markets is a huge challenge, which most firms have still to master. In this respect, there's an incredible amount of catching up to do. • 